\title{
Rhesus Monkey Mammary Tumor
}

National Cancer Institute

\section{Source}

National Cancer Institute. Rhesus Monkey Mammary Tumor. NCI Thesaurus. Code C134784.

A mammary neoplasm that occurs in a rhesus monkey. 